\title{
REPENSAR A EDUCAÇÃO AMBIENTAL: UM OLHAR CRÍTICO
}

\author{
RETHINK ENVIRONMENTAL EDUCATION: A CRITICAL LOOK
}

\author{
Walter Júnior Jovêncio de Faria ${ }^{1}$ \\ Luiz Maurício Aires F.da Silva ${ }^{2}$
}

\begin{abstract}
RESUMO
Através deste presente artigo, será apresentado o tema Repensar a Educação Ambiental: um olhar crítico. A educação ambiental é uma ação educativa que se desenvolve, através de uma prática, em que valores e atitudes promovem um comportamento rumo a mudanças perante a realidade, tanto em seus aspectos naturais como sociais, desenvolvendo habilidades e atitudes necessárias para dita transformação e emancipação e assim resgatarmos o tratado de Educação para Sociedades Sustentáveis e por novos valores que a educação ambiental se propõe formar. O objetivo deste estudo é fazer com que as pessoas possam compreender a educação ambiental crítica e emancipatória em seus compromissos com as lutas populares, com as instituições públicas e com a transformação radical das relações sociais que definem nosso modo de ser na natureza. A metodologia utilizada foi um estudo bibliográfico, exploratório, de caráter qualitativo. Como método de estudo foi utilizado o dedutivo.
\end{abstract}

Palavras-chave: Educação Ambiental, Sustentabilidade e Compromisso Social.

\begin{abstract}
Through this present article will show the theme Rethinking Environmental Education: a critical look. Environmental education is an educational activity that develops through practice, in which values and attitudes towards promoting behavior change in the face of reality, both natural and social aspects, developing skills and attitudes required for transformation and empowerment and told thus recovers the treaty of Education for Sustainable Societies and new values that environmental education is proposed to form. The aim of this study is to get people to understand the critical environmental education and emancipatory in its engagement with popular struggles, with public institutions and the transformation of social relations that define our way of being in nature. The methodology used was a literature search, exploratory, of qualitative character. As a study method was used deductive.
\end{abstract}

Words-key: Environmental Education, Sustainability and Social Commitment.

\section{Introdução}

\footnotetext{
${ }^{1}$ Especialista em Redes e Bando de Dados para Web, Mestrando em Ciências Mecânicas - UnB, Professor dos cursos de Administração, Enfermagem e Farmácia da Facer - Faculdade de Ceres, Técnico em Informática da Facer - Faculdade de Ceres; walterjun@gmail.com.

${ }^{2}$ Mestre em Gestão Estratégica de Empreendimentos pela Faculdade Alves Faria - ALFA
} 
Educação ambiental é uma prática que dialoga com a questão ambiental. E no senso comum, essa prática visa a uma mudança de valores.

Ultimamente, as sociedades se encontram com diversos fatores os quais estão relacionados aos problemas ambientais. O problema ambiental está se tornando cada vez mais visível a nosso redor. Vê-se freqüentemente as agressões ao meio ambiente, como as queimadas, os lixos químicos domésticos, industriais e hospitalares, que são diariamente depositados no solo e nos rios de forma imprópria, sem o tratamento adequado. É possível presenciar do mesmo modo também o aumento do efeito estufa, que é ocasionado pelos gases procedentes da queima de combustíveis fósseis, os quais permitem que a radiação solar adentre na atmosfera, retendo grande parte dela e causando assim, o aumento de temperatura; a utilização de agrotóxicos e o desmatamento desenfreado.

A escolha por esse tema surgiu com a preocupação vivenciada no dia-a-dia sobre a educação ambiental em nosso mundo. Os problemas ambientais atingiram tal proporção que representam hoje um verdadeiro desafio à sobrevivência da humanidade

Reconhecendo a pluralidade característica da educação ambiental e, por isso mesmo, buscando as identidades mais consistentes para responder aos desafios das condições socioambientais brasileiras, este tema apresenta algumas inovações.

Acredita-se que os conceitos da abordagem crítica e emancipatória são apresentados vinculados à prática e são, também, objeto de apreciação crítica. Por isso, o texto escolhido tem alta capacidade de traduzir os conceitos em prática e vice-versa.

Objetivo geral foi fazer com que as pessoas possam compreender a educação ambiental crítica e emancipatória em seus compromissos com as lutas populares, com as instituições públicas e com a transformação radical das relações sociais que definem nosso modo de ser na natureza. Sendo os objetivos específicos reconhecer a grande importância das relações existentes entre os indivíduos em sociedade e o meio ambiente; conscientizar as pessoas da importância de formar o indivíduo considerando a sua relação com o meio ambiente no qual está inserido; promover o processo de educação dos sujeitos para que estes percebam que o meio ambiente não é algo alheio à nossa realidade e contribuir para instaurar uma ética ecológica que promova transformações para a proteção, a recuperação e a melhoria sócio-ambiental.

A problemática encontrada é referente a falta de conscientização e informação das pessoas referente a educação ambiental. Será que os sujeitos a serem conscientizados sobre preservação da educação ambiental têm a capacidade de modificar o seu modo de vida?

Os sujeitos terão a finalidade de entender perspectiva da educação ambiental como um instrumento de reprodução social, e entendê-la além do seu reconhecido papel na mudança ambiental, também como um fator de mudança social?

Tem-se como hipótese a expectativa de empreender uma nova leitura para esse fazer educativo, reavaliando seus fundamentos e suas posturas, para no limite reconhecer que, na diversidade interna de opções político-pedagógicas da educação ambiental, invariavelmente despontam duas situações diversas como resultado da intencionalidade pedagógica: a reprodução da sociedade tal qual está, ou sua transformação.

A educação ambiental deve ser feita com compromisso social, a qual significa reestruturar a compreensão de educação ambiental, para estabelecer a conexão entre justiça ambiental, desigualdade e transformação social. Justiça e desigualdade ambiental despontam corno conceitos centrais para a educação ambiental com compromisso social, são os elementos que permitem ver com clareza a conexão entre as questões sociais e ambientais. E no campo da educação ambiental, trabalhar com processos pedagógicos vinculados à expansão da fronteira desenvolvimentista com os grupos sociais em condições de risco e vulnerabilidade ambiental permite a abordagem contextualizadora, complexa e crítica. 
Significa também uma readequação político-institucional para, na mediação pedagógica, articular as forças sociais que lutam por um mundo melhor.

\section{Educação ambiental: um compromisso social}

A educação ambiental se encontra submetida: a clássica função moral de socialização humana com a natureza, e também a pouco compreendida função ideológica de reprodução das condições sociais, reprodução esta que pode contemplar a possibilidade tanto de manutenção como de transformação social. (LAYRARGUES, 2009).

A distinção das variações político-ideológicas da educação ambiental, em que, portanto, já não é mais possível não apenas aceitar a conjugação da educação ambiental no singular, mas, sobretudo, reunir todas essas vertentes da educação ambiental no mesmo campo ideológico como se a "educação ambiental" fosse ideologicamente neutra e não representasse um fator de mudança social, evidentemente está se colocando essa prática educativa no seu devido lugar no contexto das práticas sociais de sociedades assimétricas historicamente determinadas. Isso quer dizer que reconhece-se haver, diferenças, muito comprometedor as entre as múltiplas "educações ambientais" no que diz respeito aos seus efeitos sobre a reprodução social e, também, que reconhecemos haver algumas vertentes da educação ambiental que melhor se aproximam das condições sociais dos países periféricos no capitalismo global, marcados por intensas e inaceitáveis desigualdades.

Educação ambiental com compromisso social é aquela que articula a discussão da relação entre o ser humano e a natureza inserida no contexto das relações sociais. É aquela que propicia o desenvolvimento de uma consciência ecológica no educando, mas que contextualiza seu projeto político-pedagógico de modo a enfrentar também a padronização cultural, exclusão social, concentração de renda, apatia política, além da degradação da natureza. É aquela que enfrenta o desafio da complexidade, incorporando na reflexão categorias de análise, como trabalho, mercadoria e alienação. É aquela que expõe as contradições das sociedades assimétricas e desiguais.

\footnotetext{
A educação ambiental com compromisso social não pode abrir mão da politização do debate ambiental, situando-o no terreno das doutrinas político-ideológicas e seus respectivos mecanismos de produção e reprodução social, trabalhando pelas condições ideais para os atores sociais desvelarem a realidade a que estão submetidos com todas as suas contradições, percebendo a existência das situações de desigualdade, vulnerabilidade e risco ambiental, auxiliando-os a se instrumentarem na defesa de seus direitos e interesses, motivarem-se a reagir e participar para institucionalizar a justiça ambiental, e mobilizarem-se de fato como sujeitos políticos na participação pública. (LAYRARGUES, 2009).
}

Percebe-se que os programas de educação ambiental que implementam campanhas de coleta seletiva e reciclagem, por exemplo, e que são planejados sem essa contextualização, tendem a gerar o desenvolvimento de uma consciência ecológica sem compromisso social, uma vez que reforçam a cultura consumista e os mecanismos de concentração de renda e exclusão social.

Educação ambiental é educação e, como tal, serve ou para manter ou mudar a realidade, reproduzir ou transformar a sociedade. A educação "ambiental" não só poderia como deveria ser praticada com compromisso social, pois com ela é possível contribuir com a mudança do quadro das desigualdades no País e no mundo. E o Brasil, como um dos países 
mais desiguais do mundo, tem essa questão como um contexto estruturante para a educação ambiental com compromisso social.

Segundo Jardim (2009), a educação ambiental é uma ação educativa que se desenvolve, através de uma prática, em que valores e atitudes promovem um comportamento rumo a mudanças perante a realidade, tanto em seus aspectos naturais como sociais, desenvolvendo habilidades e atitudes necessárias para dita transformação e emancipação. (JARDIM, 2009).

Assim sendo, percebe-se que a questão ambiental é conhecida como os diferentes modos pelos quais a sociedade, com o passar do tempo, se relaciona com o meio físico natural. $\mathrm{O}$ ponto chave do entendimento da problemática ambiental está na esfera da totalidade da vida em sociedade.

\subsection{A crise ambiental}

Perante do que se está sendo presenciado pela sociedade, ou melhor, dizendo, pelo mundo inteiro, assim, tem-se a capacidade de poder afirmar que nos encontramos em meio a uma crise. E o pior, uma crise ambiental. Esta afirmação foi realizada pelos cientistas do mundo inteiro nos últimos anos.

Observa-se que a crise ambiental não passou a existir de uma hora para outra, na verdade ela surgiu a alguns séculos atrás. Isso mesmo, a crise ambiental é o conjunto de ações prejudicial que o homem vem ocasionar ao longo de toda a sua existência.

Segundo Layrargues (2009), a crise ambiental trouxe novos desafios para as sociedades modernas, exigindo uma alteração no rumo civilizatório, e, na tentativa de escapar da catástrofe ambiental, os sistemas sociais vêm se adaptando à nova realidade. Em graus variáveis, o sistema econômico começou a internalizar a relação entre a economia e o meio ambiente para valorar os bens ambientais que se encontram fora do mercado, a tecnologia criou á tecnologia ecoeficiente para economizar energia e recursos, a política viu nascer um partido verde para defender a causa ambiental e internalizou a variável ambiental em suas doutrinas político-ideológicas e programas de governo, o direito se ramificou com um direito ambiental contribuindo com um novo arcabouço legal normativo, a educação qualificou-se de ambiental para auxiliar no processo de sensibilização e aquisição de uma nova cultura, a religião efetuou uma releitura de suas doutrinas e fundamentos espirituais, a comunicação criou editorias na mídia para informar a população sobre a situação ambiental, e assim sucessivamente.

A mudança ambiental, ainda por se confirmar com qual grau de profundidade, provavelmente deve ser a mudança de maior importância para o destino da história humana. Mas uma mudança apenas relativamente consensuada em relação à sua imperativa necessidade por todos os atores sociais, uma vez que ela desponta no horizonte civilizatório como uma unanimidade, sem aparentemente opor grandes interesses divergentes.

Desde que os interesses econômicos, o lucro e os privilégios não sejam afetados. A comunidade ambiental representa a força social sustentabilista, àquela que em termos gerais procura mudar a relação entre o ser humano e a natureza e trabalha para que a crise ambiental seja revertida, em contraposição à força social "desenvolvimentista". (LAYRARGUES, 2009).

De acordo com Layrargues (2009), a própria comunidade ambiental deseja diferentes tipos de mudança, uns querem que sejam profundas e radicais, contemplando o âmbito ético e paradigmático, outros se contentam que sejam apenas superficiais, reformando os sistemas sociais, para que a mudança ambiental seja efetuada mantendo intactos os mecanismos de reprodução social, sem qualquer alteração das relações de poder, e o fato é que estes interesses se confundem com os das forças desenvolvimentistas. 
O fato é que os efeitos da crise ambiental já são sentidos na vida cotidiana dos seres humanos, e uns são mais vítimas dos danos ambientais do que outros, a ponto de terem sido cunhados novos conceitos definidores desse fenômeno: fala-se de risco e vulnerabilidade ambiental a que determinados grupos sociais são submetidos, quando suas condições de vida ou de trabalho são ameaçadas em função da degradação ambiental, que, por sua vez, provoca conflitos socioambientais polarizados entre sujeitos sociais que se beneficiam da geração de riqueza a partir da exploração dos recursos ambientais, demandando, então, justiça ambiental. (LAYRARGUES, 2009).

De acordo com Layrargues (2009), para que coletividades que normalmente já se encontram em condições de vulnerabilidade social, econômica e política também não se encontrem em condições de vulnerabilidade ambiental, como os moradores de encostas de morros e margens de rios dos centros urbanos destituídos de políticas habitacionais decentes; trabalhadores de empreendimentos produtivos que são vítimas de riscos tecnológicos e das condições de insalubridade do trabalho; comunidades rurais dependentes de recursos naturais, como as populações ribeirinhas, indígenas e extrativistas de modo geral, que vêem suas atividades de subsistência ameaçadas pela expansão da fronteira agrícola moderna, pela invasão turística, pela criação de Unidades de Conservação, pela mineração, entre outros.

Percebe-se que os conflitos ambientais desrespeitam os direitos mais básicos do ser humano, seja no ambiente original de vida, como numa comunidade remanescente quilombola atingida pela construção de uma barragem, seja no ambiente de trabalho, como na indústria do amianto, que contamina o trabalhador.

Segundo Herculano (2002 justiça ambiental é:

O conjunto de princípios que asseguram que nenhum grupo de pessoas, sejam grupos étnicos, raciais ou de classe, suporte uma parcela desproporcional, das consequências ambientais negativas de operações econômicas, de políticas ou programas federais, estaduais e locais, bem como resultantes da ausência ou omissão de tais políticas. Ou seja, justiça ambiental é o princípio em que os custos ambientais devem ser distribuídos de maneira justa entre a sociedade. Complementarmente, entende-se por injustiça ambiental o mecanismo pelo qual sociedades desiguais destinam a maior carga dos danos ambientais do desenvolvimento a grupos sociais de trabalhadores, populações de baixa renda, grupos raciais discriminados, populações marginalizadas e mais vulneráveis.

Ainda Herculano (2002), salienta que o conceito de justiça ambiental representa justamente a oportunidade para introduzir no campo ambiental a perspectiva das desigualdades sociais. A ótica da justiça ambiental analisa a poluição ambiental de modo geral pela perspectiva das hierarquias sociais, ou seja, pelas classes sociais. Assim, torna-se evidente que sustentabilidade, além de proteger a natureza para as gerações futuras, é também uma questão de justiça social no tempo presente, entre as gerações atuais.

Segundo Quintas (2009), para aqueles que vêem a crise para além da questão do desenvolvimento, a saída está na reinvenção do modo dos humanos se relacionarem com $a$ natureza e entre si, abolindo a dominação inerente à organização social vigente, mesmo reconhecendo a necessidade de diminuição e/ou de mitigação dos impactos socioambientais, durante o processo de transição da atual ordem social para outra sustentável. De outro modo, não haverá nem reforma nem reinvenção.

\subsection{Gestão ambiental pública \& educação ambiental}

De acordo com Quintas (2009), é bem claro os limites da gestão ambiental pública praticada pelos Estados Nacionais para lidar com a crise ambiental. No caso do Brasil, tem-se 
uma Constituição que estabelece, no seu artigo 225, o meio ambiente ecologicamente equilibrado como um direito da população (Brasil, 1988) e uma legislação infraconstitucional considerada bastante satisfatória.

Este ordenamento jurídico permite que o Poder Público, ao promover o ordenamento da apropriação social dos recursos ambientais, crie e gerencie áreas protegidas, estabeleça padrões de qualidade ambiental, licencie atividades efetiva e potencialmente poluidoras, discipline o uso dos recursos ambientais, realize a fiscalização ambiental, promova a educação ambiental, processe criminalmente os autores de agressões ambientais e pratique uma série de outras ações objetivando a proteção e a defesa do meio ambiente. Como a gestão ambiental pública se processa numa sociedade estruturalmente insustentável, as ações praticadas com base na legislação são necessárias, mas não suficientes para reverter o quadro de crise.

Neste contexto, a prática da educação ambiental está tensionada pelas duas vertentes. A opção por uma delas implicará, necessariamente, a adoção de concepções e práticas pedagógicas, com finalidades bastante distintas, compatíveis com a escolha assumida.

\begin{abstract}
Uma proposta de educação ambiental identificada com o viés reformista buscará promover a mudança de conduta do sujeito, em sua relação cotidiana e individualizada com o ambiente e com os recursos naturais, objetivando a formação de hábitos ambientalmente responsáveis no meio social. Algo como suporte educativo às atividades para economizar energia, aumentar a produtividade dos recursos ambientais, estimular a ecoeficiência, aumentar o ciclo de vida dos equipamentos e da infraestrutura etc. (QUINTAS, 2009).
\end{abstract}

A ideia implícita nesta concepção é de que, se cada um passasse a consumir apenas o necessário (aqueles que podem), a reaproveitar ao máximo os produtos utilizados e a transformar os rejeitos em coisas úteis, em princípio, estariam "fazendo a sua parte" para economizar recursos naturais, energia e evitar a degradação ambiental. E, desta forma, contribuindo para minimizar os impactos ambientais negativos. Os detentores deste comportamento também tenderiam a consumir produtos ecologicamente corretos e, assim, estimulariam as empresas a adotarem práticas sustentáveis em seus processos produtivos.

Assim, a superação da crise ambiental seria o resultado do somatório de ações individuais decorrentes da transformação da conduta de cada pessoa, na sua relação com a natureza. E a sustentabilidade seria atingida quando todos adotassem práticas sustentáveis, cotidianamente, na sua esfera de ação. Esta abordagem evidencia uma leitura a crítica e ingênua sobre a problemática ambiental e aponta para uma prática pedagógica prescritiva e reprodutiva.

Abordagem esta que também é coerente com a perspectiva de mudança social da vertente funcionalista da Sociologia.

Segundo Quintas (2009), no nosso país, cabe ao Estado praticar a gestão ambiental pública, ordenando o processo de apropriação social dos recursos ambientais na sociedade, por meio dos instrumentos estabelecidos na legislação. Neste processo o Poder Público media interesses e conflitos, potenciais ou explícitos, entre atores sociais, sobre os modos de destinação dos recursos ambientais no meio social. Esta definição é produto de consensos construídos com atores sociais envolvidos (os quais não devem ser confundidos com unanimidade), sobre o uso e o não uso; quem, como, onde, quanto e para que usa; e quando, por quanto tempo etc. se usam os recursos naturais.

Entende-se que tudo isto necessita ser praticado nos limites da legislação, com a finalidade de garantir à população brasileira o direito ao meio ambiente ecologicamente equilibrado, conforme determina a Constituição Federal. Todavia, este processo também define e redefine como se distribuem em termos sociais e espaciais, no presente e no futuro, 
os custos e benefícios decorrentes do processo decisório sobre os modos de apropriação dos recursos ambientais na sociedade.

Portanto, a prática da gestão ambiental não é neutra. O Estado, ao assumir determinada postura diante de um problema ambiental, está de fato definindo quem ficará, na sociedade e no país, com os custos, e quem ficará com os benefícios advindos da ação antrópica sobre o meio, seja ele físico, natural ou construído (QUINTAS \& GUALDA, 1995).

Assim, quando o órgão ambiental licencia um empreendimento ou nega o seu licenciamento, estabelece o período do defeso de determinado recurso pesqueiro, cria uma Unidade de Conservação, proíbe ou impõe regras para o desmatamento e a extração de determinado recurso florestal ou, ainda, embarga uma atividade ilegal, também estará definindo quem na sociedade ficará com o ônus e quem ficará com o bônus, decorrentes do ato de gestão ambiental praticado.

Conforme Loureiro (2006), a gestão ambiental pública foi instituída para garantir o direito constitucional ao meio ambiente ecologicamente equilibrado, é um processo de mediação de interesses e conflitos. A gestão ambiental, além de não ser neutra, distribui custos e benefícios de modo assimétrico na sociedade.

\subsection{Sustentabilidade ambiental}

As preocupações ambientais referentes o nosso planeta aumentam cada dia mais, e nas últimas décadas encontram-se entre os mais sérios desafios que afetam o bem-estar das pessoas em todo o mundo. Todas as nações são afetadas, mas geralmente os países mais pobres e as populações menos privilegiadas sofrem o maior ônus. Elas são as mais atingidas pela destruição ambiental e a mudança climática e são as que têm o menos recursos disponíveis para adaptar-se às situações de mudança. (THOMÁS, 2008).

A gestão ambiental, impulsionada pela educação, pode contribuir para que formas de regulação ambiental possam ser explicitadas e internalizadas, enfatizando o compromisso de todos os setores da sociedade civil na promoção da sustentabilidade.

\footnotetext{
Uma gestão ambiental sustentável deverá permear todos os setores da sociedade, constituindo-se, basicamente, em um processo inteligente de negociação de propósitos, aparentemente diferente, mas que, com certeza, podem ser mediados, visando à conciliação do interesse do desenvolvimento da sociedade humana, por meio da manutenção do equilíbrio ambiental, em que a sociedade e o poder público cobrarão e implementarão ações preconizadas, dentro de uma visão incorporada de totalidade. (PIMENTEL, 2006, p. 65).
}

Os instrumentos de participação na gestão ambiental, que se apresentam como fundamentais pela articulação poder público e sociedade são os conselhos de meio ambiente (municipais, estadual e nacional), que, formados pela sociedade civil, empresas, instituições de ensino e poder público, ficam encarregados de estabelecer normas e padrões de desenvolvimento, condizentes com a melhoria da qualidade de vida e de responsabilizar-se pela fiscalização e avaliação dos processos produtivos.

Segundo Marrul Filho (2003), a sustentabilidade se vincula a ele e à lógica das práticas humanas. Assim, se constitui historicizada e é socialmente construída, tendo raízes em questões como: sustentabilidade do que, para quem, quando, onde, por que, por quanto tempo. Isso significa que os atores sociais se movem, em seus discursos e práticas, buscando legitimá-los, ou sendo por outro(s) deslegitimizados, de modo a prevalecerem aqueles(as) [discursos e práticas] que vão construir autoridade para falar em sustentabilidade e, assim, discriminar, em seu nome, aquelas práticas que são sustentáveis ou não. 
E ainda alertando que a noção de sustentabilidade é fundamentalmente relacional, o autor Marrul Filho (2003, p. 87) lembra que "a construção tanto da autoridade como da discriminação de práticas boas ou ruins, constituem uma relação temporal entre passado, presente e futuro".

\begin{abstract}
É sustentável hoje aquele conjunto de práticas portadoras de sustentabilidade no futuro". Assim, a condição para uma sociedade, um grupo social ou um indivíduo avaliarem se determinada prática, em determinado momento, é sustentável ou não (e consequentemente sobre a conveniência de adotá-la dependerá, fundamentalmente, do caráter que ela irá assumir no futuro. Portanto, há um vínculo indissolúvel entre as ações do presente e as do futuro. E como essas ações são realizadas para a satisfação de necessidades humanas presentes e futuras, fica o problema, ainda, de se lidar no presente com algo (necessidades) cuja veracidade estará explícita em outro tempo. (MARRUL FILHO, 2003, p. 87).
\end{abstract}

A discussão sobre a construção da sustentabilidade no tempo presente está vinculada à quantidade de bens ambientais que é extraída da natureza para a satisfação das necessidades das presentes gerações, sem que se inviabilize as gerações futuras. Significa também entender o que são necessidades humanas e como elas podem ser satisfeitas de maneira sustentável. O conceito de necessidade, além de seu conteúdo subjetivo no plano do indivíduo, possui um conteúdo histórico e cultural, e por si não é capaz de descrever um estado fixo, imutável, para todas as sociedades do planeta, e, sobretudo, para as futuras gerações sustentabilidade não é um problema técnico que pode ser resolvido por meio da escolha de práticas "sustentavelmente adequadas" (reciclagem de resíduos, por exemplo), propostas por especialistas em várias áreas de conhecimento. Ainda que se reconheça a importância da ciência e da tecnologia no processo de busca da sustentabilidade, sua contribuição é condição necessária, jamais suficiente.

Segundo Marrul Filho (2003, p. 86), "quando se fala em sustentabilidade há sempre que se perguntar: "sustentabilidade do que, para quem, quando, onde, por que, por quanto tempo.

\title{
2.4 Educação \& gestão ambiental: construção do ato pedagógico
}

Segundo Quintas (2009), quando se fala em construção do ato pedagógico, está se falando num processo que vai do planejamento até a sua realização. $\mathrm{O}$ ato, ação ou processo pedagógico, ou ação educativa, ou processo de ensino-aprendizagem, ou prática educativa é o lugar da concretização dos pressupostos de qualquer proposta de educação. Logo, trata-se de se colocar o discurso na prática, mostrando inclusive o quanto esta prática é leal à concepção enunciada.

Quintas (2009), defende-se uma educação crítica, transformadora e emancipatória, que tem como finalidade contribuir para a construção de uma sociedade justa, democrática e sustentável e como propósito imediato a intervenção qualificada, coletiva e organizada de grupos sociais específicos no ordenamento das práticas de apropriação dos bens ambientais na sociedade que o Estado realiza ou deixa de realizar.

Para dar partida ao planejamento da ação educativa é necessário que a equipe de educadores defina os seus objetivos, ou seja, a sua intencionalidade, mesmo admitindo, a priori, a possibilidade de mudá-los, se houver necessidade, ao longo do processo pedagógico. Um ato pedagógico, para ser digno deste nome, deve explicitar seus objetivos (inclusive os de aprendizagem), independentemente da concepção de educação assumida. Pois sendo a Educação uma prática política, o ato pedagógico será sempre portador de uma 
intencionalidade, seja de forma implícita ou explícita. Portanto, não há prática educativa neutra. (QUINTAS, 2009).

\subsection{O evangelho da ecoeficiência}

Para Amâncio et al (2009, apud, Alier, 2007), o evangelho da ecoeficiência, se preocupa com os efeitos do crescimento econômico. Seu olhar esta voltado para os impactos ambientais e/ou riscos à saúde decorrentes das atividades industriais, da urbanização e também da agricultura moderna. Geralmente defende o crescimento econômico, contudo pondera a necessidade de se repensar processos, meios e formas para se alcançar esse crescimento. Acredita, de maneira geral, que o processo de industrialização é irreversível e desta maneira apregoa a expectativa de um desenvolvimento tecnológico que diminua ou mitigue os impactos do processo de crescimento econômico industrial.

Segundo Loureiro et al (2009), o evangelho da ecoeficiência, preocupa-se com os impactos da produção de bens e com o manejo sustentável dos recursos naturais, e não tanto com a perda dos atrativos da natureza ou dos seus valores intrínsecos.

Tanto a ecoeficiência quanto o conservacionismo são correntes legitimadas pela ideologia dominante, ou seja, funcionam segundo a lógica do mercado ou sem questioná-la, naturalizando as relações sociais vigentes, não existindo, portanto, preocupação em alterar a estrutura do sistema político-econômico hegemônico. Até mesmo por isso, são aceitos sem dificuldades pela opinião pública e reproduzidos largamente pelos meios de comunicação de massa, dado que reforçam o senso comum do que é mais indicado para os problemas e ameaças ao ambiente natural. "Ao longo do tempo, essas correntes têm-se tornado complementares, dado que as ações de uma não se opõem às da outra". (LOUREIRO et al, 2009, p. 82).

Percebe-se que ao afirmar que as mudanças tecnológicas tomarão compatível a produção de bens com a sustentabilidade ecológica, enfatizam a preservação daquela parte da natureza que, ainda, se mantivera fora da economia.

\subsection{Conflitos ambientais no processo de reestruturação de forças no campo ambiental}

De acordo com Loureiro et al (2009, p. 104), "o ambiente se constitui como um território comum. Contudo, é um território conflituoso, pois nele estão envolvidas relações de uso e apropriação material e de concorrência e dominação por formas culturais de existência". O ambiente é dotado então de um cará ter distributivo, dado que suas representações em busca de hegemonia envolvem disputas por projetos de sociedade, ou seja, "para que", "para quem" e "como" devem ser a natureza, os recursos naturais, os bens materiais, a qualidade ambiental. Por essa ótica, o ambiente define-se contraditoriamente, pois, em uma sociedade de classes, a existência de certos benefícios para uns requer a privação dos mesmos para outros. Os conflitos ambientais, portanto, explicam o caráter desigual a que estão submetidos os grupos sociais em determinado espaço territorial.

Acselrad (2004) advoga que podemos pensar em dois espaços em que se definem as relações de poder nas sociedades, e que são pertinentes aos modos de apropriação da base material da sociedade:

O primeiro é o espaço da distribuição, entre os sujeitos sociais, do poder sobre os diferentes tipos de "capital", incluindo o que podemos chamar, para efeitos da questão ambiental, de "capital material". (...) O segundo é o espaço em que se confrontam as representações, valores, esquemas de percepção e ideias que organizam as visões de mundo e legitimam os modos de distribuição de poder verificador no primeiro espaço. (ACSELRAD, 2004, p. 23). 
Os conflitos socioambientais localizados em determinado território devem ser analisados tanto pelas diferentes forças sociais disputando a materialidade dos volumes de capital específicos, como pela luta que legitima a distribuição de poder, que é simbólica, dinâmica em um processo criativo de invenção e reformulação de novos sentidos.

No caso do meio ambiente, verificamos no primeiro espaço, por exemplo, disputas por apropriação dos rios entre populações ribeirinhas e grandes projetos hidroelétricos, empates confrontando seringueiros e latifundiários pelo controle de áreas de seringais etc. "No espaço das representações, veremos disputas entre distintas formas sociais de apropriação do território pela afirmação de seus respectivos caracteres competitivo, sustentável, compatível com a vocação do meio, ambientalmente benigno, etc". (ACSELRAD, 2004, p. 23).

De acordo com a citação, é possível perceber que as representações que dão sentido ao campo podem ser apropriadas de várias formas, pois expressam conceitos que possuem uma pluralidade de leituras e que significam formas específicas de se apropriar materialmente da natureza. Por outro lado, diferentes formas culturais de se apropriar do ambiente não desencadeiam necessariamente conflitos. As formas culturais só incitam conflitos ambientais a partir da tentativa de universalizar-se ou expandir-se no tecido social como a forma válida de se relacionar com a natureza, tanto no sentido ideológico como no objetivo e material, gerando disputas entre agentes com interesses antagônicos. Os conflitos ambientais emergem, assim, a partir do momento em que a utilização dos recursos de certos grupos concorre com outros grupos, afetando a reprodução social de condições de existência. Dessa forma, podemos definir conflitos ambientais como:

Aqueles envolvendo grupos sociais com modos diferenciados de apropriação, uso e significação do território, tendo origem quando pelo menos um dos grupos tem a continuidade das formas sociais de apropriação do meio que desenvolvem ameaçada por impactos indesejáveis — transmitidos pelo solo, água, ar ou sistemas vivos — decorrentes do exercício das práticas de outros grupos. (ACSELRAD, 2004, p. 26)

Nessa perspectiva, pode-se presumir que mudanças na conformação de determinado território, que afetem a sobrevivência de grupos sociais, tendem a encadear conflitos. Isso significa dizer que aqueles que não são diretamente dependentes do modelo hegemônico de desenvolvimento, dado que não estão inseridos no mercado capitalista ou em seus mecanismos de reprodução, tendem a sentir o impacto de modo intenso, pois a expropriação de um território que oferece os benefícios ambientais para esses grupos é sinônimo de perda não somente do seu lugar de moradia, mas também de seu trabalho e sua cultura. É o caso do movimento dos atingidos por barragens, dos trabalhadores rurais sem-terra, dos pescadores artesanais, dos pequenos agricultores, dos grupos quilombolas, dos seringueiros etc. (LOUREIRO, et al, 2009).

\subsection{Metodologia}

O presente artigo caracteriza-se como um estudo bibliográfico, exploratório, de caráter qualitativo. Como método de estudo será utilizado o dedutivo.

Segundo Brito \& Arns (2006), a pesquisa bibliográfica abrange toda a bibliografia já tornada pública em relação ao tema de estudo, desde publicações avulsas, boletins, jornais, revistas, livros, pesquisas, monografias, teses, material cartográfico e meios de comunicação como rádio, gravações em fita magnética e audiovisuais (filmes e televisão). 
Os principais objetivos da pesquisa bibliografica são: Conhecer as diferentes contribuições científicas disponíveis sobre determinado tema e Atualização do pesquisador, evitando-se duplicação de pesquisas.

A pesquisa exploratória tem por objetivo proporcionar maior familiaridade com o problema (fenômeno a ser investigado), com vistas a torná-lo mais explícito ou a construir hipóteses.

Sendo uma pesquisa qualitativa, segundo Minayo (1999) coloca que a pesquisa qualitativa se preocupa, nas ciências sociais, com um nível de realidade que não pode ser quantificado. Ou seja, ela trabalha com um universo de significados, motivos, aspirações, crenças, valores e atitudes, o que corresponde a um espaço mais profundo das relações, dos processos e dos fenômenos que não podem ser reduzidos à operacionalização de variáveis. Na pesquisa qualitativa, o material utilizado é a palavra, que expressa a fala cotidiana, nos discursos intelectuais, burocráticos, políticos e nas relações afetivas ou técnicas. Neste método, procura-se interpretar o conteúdo das falas, ultrapassando a mensagem e conhecendo significados latentes.

$\mathrm{O}$ método utilizado a ser utilizado será o dedutivo $\mathrm{O}$ método dedutivo tem o propósito de explicitar o conteúdo das premissas, pois parte do geral para se chegar às particularidades. Já o método indutivo tem a finalidade de ampliar o alcance dos conhecimentos. (BARROS E LEHFELD, 2000).

\section{Considerações finais}

Após chegar ao término deste estudo percebe-se o quanto a educação é um processo contínuo e duradouro, o processo de aprendizagem é um fator relevante na formação do sujeito e da cidadania, pois o processo de aprendizagem tem início quando o indivíduo nasce e só termina quando a vida cessa, pois a aprendizagem acontece de modo permanente durante a vida doméstica, escolar e social. Permanecendo durante todo o tempo em que a mente se mantenha ativa.

Neste contexto a educação ambiental tem papel relevante e deve está incluso de modo mais abrangente, hoje é preciso mudar individualmente para se mudar a coletividade, ou seja, é preciso agir localmente e pensar globalmente, pois a coletividade o principal eixo das grandes mudanças seja elas, sociais, intelectuais e educacionais, o homem precisa aprender a dividir, a sociabilizar principalmente o conhecimento.

Sabe-se que a crise ambiental não surgiu de uma hora para outra, haja vista que ela é resultado das ações danosas do homem para com o meio ambiente ao longo de sua existência. E assim, essa crise tem por decorrência os próprios resultados das ações predatórias do ser humano.

É possível observar que para solucionar essa crise será necessária a união de todos, onde cada um tem a capacidade de fazer a sua parte. É preciso se valer do Direito em si, ou seja, das leis, da conscientização e respeito ao meio ambiente; da participação da sociedade; do Poder Público, para que assim, ele possa investir na educação ambiental e buscar meios para realizar a fórmula do desenvolvimento sustentável.

Por fim, conclui-se que é preciso haver implicações para a educação ambiental com compromisso social, onde deva considerar a mudança social na educação ambiental, ou seja, assumir o compromisso por uma educação ambiental com responsabilidade social, empenhada também na transformação social, implica uma reelaboração conceitual, mas também assumir outras posturas decorrentes da incorporação da perspectiva da questão ambiental como uma questão de justiça distributiva, para uma coerente tradução nas estratégias de ação das práticas pedagógicas da educação ambiental. 


\section{Referências bibliográficas}

ACSELRAD, H. As práticas espaciais e o campo dos conflitos ambientais. Rio de Janeiro: Relume Dumará, 2004.

AMÂNCIO, Robson et al. Desenvolvimento sustentável e recursos naturais: uma leitura estruturalista da questão ambiental. 2009. Disponível em http://starline.dnsalias.com:8080/sbs/arquivos/30_6_2009_23_4_8.pdf. Acesso em: 15/08/2010.

BARROS, Aidil Jesus da Silveira; LEHFELD, Neide Aparecida de Souza. Fundamentos de Metodologia Científica: um guia para a iniciação científica. 2. ed. São Paulo: Makron Books, 2000 .

BRITO, Maria Cristina Cachenski \& ARNS, José Fernando. III Encontro da ANPPAS. Disponível no site: www.anppas.org.br/encontro_anual/encontro3/arquivos/TA480-0403200602634.DOC. Acesso em: 11/08/2010.

HERCULANO, S. Riscos e Desigualdade social: a temática da justiça ambiental e sua construção no Brasil. Paper apresentado no I Encontro da ANPPAS. Indaiatuba: ANPPAS, 2002.

JARDIM, Daniele Barros. A Educação Ambiental e suas Trajetórias, Fundamentos e Identidades. 2009. Disponível em:

http://www.revistaea.org/artigo.php?idartigo=711\&class=02. Acesso em: 13/08/2010.

LAYRARGUES, Philippe Pomier. (org) Repensar a educação ambiental: um olhar crítico. São Paulo, Cortez, 2009.

LOUREIRO, C. F. B et al. Repensar a educação ambiental: um olhar crítico. São Paulo, Cortez, 2009.

Problematizando conceitos: contribuição à práxis em educação ambiental. In: LOUREIRO, C. F. B.; LAYRARGUES, P. R; CASTRO, R. S. (Org.). Pensamento complexo, dialética e educação ambiental. São Paulo: Cortez, 2006.

MINAYO, M.C.S. (Org.) Pesquisa social: teoria, método e criatividade. 13. ed. Petrópolis: Vozes, 1999.

PIMENTEL, C.E. Gestão Ambiental para o turismo. In:Queiroz, O.T.M.M. (org). Turismo e ambiente: temas emergentes. Campinas,SP:Alínea, 2006.

QUINTAS, José Silva. Repensar a educação ambiental: um olhar crítico. São Paulo, Cortez, 2009. 
GUALDA, M. J. A formação do educador para atuar no processo de gestão ambiental. Brasília: Edições Ibama, 1995.

THÓMAS, Vinod. Sustentabilidade Ambiental. 2008. Disponível em http://siteresources.worldbank.org/extenvironment/Resources/EvalSumm_port.pdf. Acesso em: 18/08/2010. 